\title{
Studi Pengenalan Internet of Things Bagi Guru dan Siswa SMK Bina Nusa Slawi Sebagai Wawasan Salah Satu Ciri Revolusi Industri 4.0
}

\author{
Ginanjar Wiro Sasmito*1, Sena Wijayanto², La Ode Mohamad Zulfiqar ${ }^{3}$ \\ 1,2,3Program Studi D IV Teknik Informatika Politeknik Harapan Bersama \\ *e-mail: anjar.dosen@gmail.com
}

\begin{abstract}
Bina Nusa Slawi Vocational School (Binus) is one of the Vocational High Schools located in Slawi District, Tegal Regency. The results of a survey conducted, that almost all teachers and students (99\%) had heard about the Industrial Revolution 4.0 and Internet of Things, but did not understand the meaning of it all, even though the industrial revolution 4.0 had disrupted almost all fields of science and lines of life. The survey results also show that all teachers and students have used internet maximally, but development trend of the use internet that is not yet widely understood, especially regarding: Wireless Sensor Network (WSN), Cloud Computing, Big Data, and Artificial Intelligence. Therefore needed an Introduction Study Internet of Things for Teachers and Students of SMK Bina Nusa Slawi as Insights One of the Characteristics of the Industrial Revolution 4.0. The method implemented is by giving presentations, discussions, and demonstrations about Internet of Things, Artificial Intelligence and Big Data. Based on activities that have been carried out, the results obtained are knowledge, understanding, competence of teachers and students of SMK Bina Nusa Slawi about Internet of Things increasing.
\end{abstract}

Keywords: Internet of Things, Industrial Revolution 4.0, SMK Bina Nusa Slawi

\begin{abstract}
Abstrak
SMK Bina Nusa Slawi (Binus) merupakan salah satu Sekolah Menengah Kejuruan yang terdapat di Kecamatan Slawi Kabupaten Tegal. Hasil survey yang dilakukan, bahwa hampir semua guru dan siswa (99\%) telah mendengar mengenai Revolusi Industri 4.0 dan Internet of Things, akan tetapi tidak memahami makna dari itu semua, padahal revolusi industri 4.0 telah mendisrupsi hampir ke semua bidang ilmu dan lini kehidupan. Hasil survei juga menghasilkan bahwa semua guru dan siswa telah menggunakan internet secara maksimal, akan tetapi tren perkembangan dari pemanfaatan internet yang sekarang ini belum banyak yang memahami, terlebih mengenai : Wireless Sensor Network (WSN), Cloud Computing, Big Data, dan Artificial Intelligence. Oleh karena itu dibutuhkan Studi Pengenalan Internet of Things Bagi Guru dan Siswa SMK Bina Nusa Slawi Sebagai Wawasan Salah Satu Ciri Revolusi Industri 4.0. Metode yang dilaksanakan yakni dengan memberikan presentasi, diskusi, dan demonstrasi mengenai Internet of Things, Artificial Intelligence dan Big Data. Berdasarkan kegiatan yang telah dilaksanakan, maka hasil yang didapatkan adalah pengetahuan, pemahaman, kompetensi guru dan siswa SMK Bina Nusa Slawi mengenai Internet of Things semakin meningkat.
\end{abstract}

Kata kunci: Internet of Things, Revolusi Industri 4.0, SMK Bina Nusa Slawi

\section{PENDAHULUAN}

Industri 4.0 adalah nama tren otomasi dan pertukaran data terkini dalam manufaktur. Istilah ini mencakup sistem siber fisik, Internet of Things, dan komputasi awan (Hermann, Pentek, \& Otto, 2016). Tren ini telah mengubah banyak bidang kehidupan manusia, termasuk ekonomi, dunia kerja, bahkan gaya hidup manusia itu sendiri. Singkatnya, revolusi 4.0 menanamkan teknologi cerdas yang dapat terhubung dengan berbagai bidang kehidupan manusia.

Revolusi Industri 4.0 telah menunjukkan bahwa globalisasi tidak hanya fenomena yang berdampak pada bidang teknologi saja, namun telah mendisrupsi berbagai bidang lain seperti sosial, hukum, dan ekonomi. Akibat yang ditimbulkan dari disrupsi ini membuat tatanan dunia berubah drastis (Industri, Tantangan, \& Sosial, 2018). Revolusi industri 4.0 memiliki empat prinsip yang memungkinkan setiap perusahaan untuk mengidentifikasi dan mengimplementasikan berbagai skenario industri 4.0, diantaranya:

1. Interoperabilitas (kesesuaian); kemampuan mesin, perangkat, sensor, dan manusia untuk terhubung dan saling berkomunikasi satu sama lain melalui media internet untuk segalanya (IoT) atau internet untuk khalayak (IoT). 
2. Transparansi Informasi; kemampuan sistem informasi untuk menciptakan salinan dunia fisik secara virtual dengan memperkaya model pabrik digital dengan data sensor.

3. Bantuan Teknis; pertama kemampuan sistem bantuan untuk membantu manusia mengumpulkan data dan membuat visualisasi agar dapat membuat keputusan yang bijak. Kedua, kemampuan sistem siber-fisik untuk membantu manusia melakukan berbagai tugas yang berat, tidak menyenangkan, atau tidak aman bagi manusia.

4. Keputusan Mandiri; kemampuan sistem siber-fisik untuk membuat keputusan dan melakukan tugas semandiri mungkin.

Salah satu ciri dari revolusi industri 4.0 adalah dengan adanya pemanfaatan Internet of Things (IoT) yang merupakan sebuah konsep/skenario dimana suatu objek yang memiliki kemampuan untuk mentransfer data melalui jaringan tanpa memerlukan interaksi manusia ke manusia atau manusia ke komputer (Zhou, Qilou \& Zhang, 2011). IoT muncul sebagai isu besar di internet, diharapkan bahwa miliaran hal fisik atau benda akan dilengkapi dengan berbagai jenis sensor yang terhubung ke internet melalui jaringan serta dukungan teknologi seperti tertanam sensor dan aktualisasi, frekuensi radio Identifikasi (RFID), jaringan sensor nirkabel real - time dan layanan web, IoT sebenarnya cyber fisik sistem atau jaringan dari jaringan. Dengan jumlah besar hal / benda dan sensor / aktuator yang terhubung ke internet, besar - besaran dan dalam beberapa kasus aliran data real - time akan otomatis dihasilkan oleh hal - hal yang terhubung dan sensor. Dari semua kegiatan yang ada dalam IoT adalah untuk mengumpulkan data mentah yang benar dengan cara yang efisien; tapi yang lebih penting adalah untuk menganalisis dan mengolah data mentah menjadi informasi lebih berharga (Elkhodr, Shahrestani, \& Cheung, 2012).

Optimalisasi Internet of Things (IoT) saat ini sangat banyak di harapkan, hal ini tidak terlepas dari pemanfaatan Wireless Sensor Network (WSN), Cloud Computing, Big Data, Software Engineering dan Artificial Intelligence (Keoh, Kumar, \& Tschofenig, 2014).

SMK Bina Nusa Slawi (Binus) merupakan salah satu Sekolah Menengah Kejuruan yang terdapat di Kecamatan Slawi Kabupaten Tegal yang didirikan oleh Yayasan Bina Nusa Mandiri. SMK Binus memiliki program keahlian sebagai berikut:

1. Teknik Komputer dan Jaringan

2. Multimedia

3. Farmasi

4. Otomotif (Teknik Sepeda Motor)

5. Perbankan

6. Teknik Produksi dan Program Penyiaran Radio dan Pertelevisian (TP3RP).

Berdasarkan data bulan September 2019, bahwa SMK Binus memiliki jumlah guru = 75 orang, karyawan $=14$ orang dan jumlah siswa $=1076$ orang dengan rata-rata domisili berasal dari satu Kecamatan yang sama pada sekolah tersebut.

Guru di SMK Muhammadiyah dibagi kedalam 3 kompetensi yang ada, yakni: Adaptif, Normatif dan Produktif. Adapun klasifikasinya adalah sebagai berikut:

Tabel 1. Deskripsi Kompetensi Guru

\begin{tabular}{ll}
\hline \multicolumn{1}{c}{ Kompetensi } & \multicolumn{1}{c}{ Mata Pelajaran } \\
\hline Adaptif & Bahasa Inggris \\
& Matematika \\
& Fisika \\
& Kimia \\
& IPS \\
& Kewirausahaan \\
\hline Normatif & Pendidikan Agama \\
& Kewarganegaraan \\
& Bahasa Indonesia \\
& Pendidikan Jasmani Olah Raga dan Kesehatan \\
& Seni Budaya \\
\hline
\end{tabular}




\begin{tabular}{ll}
\cline { 2 - 2 } & Bimbingan Konseling \\
& Kemuhammadiyahan \\
\hline Produktif & Teknik Komputer dan Jaringan \\
& Multimedia \\
& Farmasi \\
& Otomotif \\
& Perbankan \\
& Teknik Produksi dan Program Penyiaran Radio dan \\
& Pertelevisian (TP3RP). \\
\hline
\end{tabular}

Berdasarkan data pada tabel 1 tersebut diatas, Guru yang terdapat pada SMK Binus tersebut secara kompetensi tergolong heterogen sesuai dengan bidang ilmunya, terlebih dengan siswa yang terdapat pada program keahlian sesuai peminatan masing-masing. Hasil survey yang dilakukan, bahwa hampir semua guru dan siswa (99\%) telah mendengar mengenai Revolusi Industri 4.0 dan Internet of Things, akan tetapi tidak memahami makna dari itu semua, padahal revolusi industri 4.0 itu mendisrupsi hampir ke semua bidang ilmu dan lini kehidupan.

Hasil survei juga menghasilkan bahwa semua guru dan siswa telah menggunakan internet secara maksimal, akan tetapi tren perkembangan dari pemanfaatan internet yang sekarang ini belum banyak yang memahami, terlebih mengenai : Wireless Sensor Network (WSN), Cloud Computing, Big Data, dan Artificial Intelligence. Oleh karenanya dalam Pengabdian Masyarakat ini maka diambil judul mengenai : Studi Pengenalan Internet of Things Bagi Guru dan Siswa SMK Bina Nusa Slawi Sebagai Wawasan Salah Satu Ciri Revolusi Industri 4.0 dengan tujuan untuk menerapkan Tri Dharma Perguruan Tinggi dalam bidang Pengabdian Masyarakat dan menerapkan IPTEK kepada guru dan siswa SMK Bina Nusa Slawi mengenai Internet of Things (IoT).

Beberapa teori yang dijadikan landasan dalam melaksanakan kegiatan pengabdian masyarakat ini diantaranya :

\subsection{Revolusi Industri 4.0}

Globalisasi telah memasuki era baru yang bernama Revolusi Industri 4.0. Klaus melalui The Fourth Industrial Revolution menyatakan bahwa dunia telah mengalami empat tahapan revolusi, yaitu: 1) Revolusi Industri 1.0 terjadi pada abad ke 18 melalui penemuan mesin uap, sehingga memungkinkan barang dapat diproduksi secara masal, 2) Revolusi Industri 2.0 terjadi pada abad ke 19-20 melalui penggunaan listrik yang membuat biaya produksi menjadi murah, 3) Revolusi Industri 3.0 terjadi pada sekitar tahun 1970an melalui penggunaan komputerisasi, dan 4) Revolusi Industri 4.0 sendiri terjadi pada sekitar tahun 2010 an melalui rekayasa intelegensia dan internet of thing sebagai tulang punggung pergerakan dan konektivitas manusia dan mesin (Shwab, 2016).

Perkembangan teknologi informasi yang pesat saat ini menjadikan sistem otomatisasi yang terjadi diseluruh bidang, teknologi dan pendekatan baru yang menggabungkan secara nyata, digital dan secara fundamental (Tjandrawinata, 2016). Beberapa tantangan yang dihadapi pada era industri 4.0 yaitu masalah keamanan teknologi informasi, keandalan stabilitas mesin produksi, kurangnya keterampilan yang memadai, ketidakmampuan untuk berubah oleh pemangku kepentingan, dan hilangnya banyak pekerjaan karena berubah menjadi otomatisasi.

Revolusi industri 4.0 dikenal dengan revolusi digital karena terjadi proliferasi komputer dan otomatisasi pencatatan disemua bidang, karena otomatisasi dan konektivitas disebuah bidang akan membuat perubahan secara signifikan di dunia industri dan persaingan kerja menjadi tidak linier.Salah satu karakteristik dari revolusi industri 4.0 menerapkan pengaplikasikan kecerdasan buatan atau artificiall intelligence.

\subsection{Teknologi Informasi}

Teknologi informasi (Information Technology) biasa disingkat TI, IT atau Information Technology. Dalam Oxford English Dictionary (OED2) edisi ke-2 mendefenisikan teknologi informasi adalah hardware dan software, dan bisa termasuk di dalamnya jaringan dan 
telekomunikasi yang biasanya dalam konteks bisnis atau usaha. Teknologi informasi adalah seperangkat alat yang membantu anda bekerja dengan informasi dan melakukan tugas-tugas yang berhubungan dengan pemrosesan informasi (Kadir, 2005). Teknologi informasi merupakan teknologi yang menggabungkan komputasi (komputer) dengan jalur komunikasi kecepatan tinggi yang membawa data, suara, dan video (William and Sawyer, 2007).

Berbeda antara teknologi informasi dan sistem informasi, sistem informasi di definisikan sebagai suatu sistem didalam suatu organisasi, yang mempertemukan kebutuhan pengolahan transaksi harian, mendukung operasi, bersifat manajerial dan kegiatan strategi dari suatu organisasi dan menyediakan pihak luar tertentu dengan laporan (Supriyanto, 2005).

Pemanfaatan teknologi informasi (TI) pada sebagian besar perusahaan saat ini bukan lagi menjadi barang langka yang sulit ditemukan. Tidak dapat dipungkiri juga bahwa teknologi informasi telah menjadi kebutuhan sekaligus persyaratan bagi organisasi dalam menjalankan bisnisnya (Jogiyanto \& Abdillah, 2011).

\subsection{Internet of Things}

Pengggunaan komputer dimasa datang mampu mendominasi pekerjaan manusia dan mengalahkan kemampuan komputasi manusia seperti mengontrol peralatan elektronik dari jarak jauh menggunakan media internet, IoT (Internet of Things) memungkinkan pengguna untuk mengelola dan mengoptimalkan elektronik dan peralatan listrik yang menggunakan internet. Hal ini berspekulasi bahwa di sebagian waktu dekat komunikasi antara komputer dan peralatan elektronik mampu bertukar informasi di antara mereka sehingga mengurangi interaksi manusia. Hal ini juga akan membuat pengguna internet semangkin meningkat dengan berbagai fasilitas dan layanan internet.

Tantangan utama dalam IoT adalah menjembatani kesenjangan antara dunia fisi dan dunia informasi. Seperti bagaimana mengolah data yang diperoleh dari peralatan eletronik melakui sebuah interface antara pengguna dan peralatan itu. sensor mengumpulkan data mentah fisik dari skenario real time dan mengkonversikan ke dalam mesin format yang dimengerti sehingga akan mudah dipertukarkan antara berbagai bentuk format data (Thing) (Suresh, P.; Daniel, J. Vijay; Aswathy, 2014). Dari semua kegiatan yang ada dalam IoT adalah untuk mengumpulkan data entah yang benar dengan cara yang efisien; tapi lebih penting adalah untuk menganalisis dan mengolah data mentah menjadi informasi lebih berharga (Wang et al., 2013).

Internet of Things dalam penerapannya juga dapat mengidentifikasi, menemukan, melacak, memantau objek dan memicu event terkait secara otomatis dan real time, Pengembangan dan penerapan komputer, Internet dan teknologi informasi dan komunikasi lainnya (TIK) membawa dampak yang besar pada masyarakat manajemen ekonomi, operasi produksi, sosial manajemen dan bahkan kehidupan pribadi (Zhou, Qilou \& Zhang, 2011).

\subsection{Artificial Intelligence}

Artificial Intelligence atau lebih dikenal sebagai Kecerdasan buatan merupakan salah satu bagian ilmu komputer yang membuat agar mesin (komputer) dapat melakukan pekerjaan seperti dan sebaik yang dilakukan oleh manusia (Kusumadewi, 2003). Manusia cerdas (pandai) dalam menyelesaikan permasalahan, ini karena manusia mempunyai pengetahuan dan pengalaman. Pengetahuan diperoleh dari belajar. Semakin banyak bekal pengetahuan yang dimiliki tentu akan lebih mampu menyelesaikan permasalahan. Akan tetapi bekal pengetahuan saja tidak cukup, manusia juga diberi akal untuk melakukan penalaran, mengambil kesimpulan berdasarkan pengetahuan dan pengalaman yang dimiliki. Tanpa memiliki kemampuan untuk menalar dengan baik, manusia dengan segudang pengalaman dan pengetahuan tidak akan dapat menyelesaikan masalah dengan baik. Demikian juga dengan kemampuan menalar yang sangat baik, namun tanpa bekal pengetahuan dan pengalaman yang memadai, manusia juga tidak akan bisa menyelesaikan masalah dengan baik. Demikin juga agar mesin bisa cerdas (bertindak seperti dan sebaik manusia) maka harus diberi bekal pengetahuan, sehingga mempunyai kemampuan untuk menalar.

Untuk membuat aplikasi kecerdasan buatan ada 2 bagian utama yang sangat dibutuhkan 
1. Basis Pengetahuan (Knowledge Base), bersifat fakta-fakta, teori, pemikiran dan hubungan antar satu dengan yang lainnya.

2. Motor Inferensi (Inference Engine), kemampuan menarik kesimpulan berdasarkan pengetahuan dan pengalaman.

Penerapan kecerdasan buatan sekarang telah terdapat di berbagai sektor (publik, swasta, pemerintah, dan nirlaba) dan industry (The institute of Interbal auditors, 2017).

\subsection{Big Data}

Big Data bukanlah sebuah teknologi, teknik, maupun inisiatif yang berdiri sendiri. Big Data adalah suatu tren yang mencakup area yang luas dalam dunia bisnis dan teknologi. Big Data menunjuk pada teknologi dan inisiatif yang melibatkan data yang begitu beragam, cepat berubah, atau berukuran super besar sehingga terlalu sulit bagi teknologi, keahlian, maupun infrastruktur konvensional untuk dapat menanganinya secara efektif. Dengan kata lain, Big Data memiliki ukuran (volume), kecepatan (velocity), atau ragam (variety) yang terlalu ekstrim untuk dikelola dengan teknik konvensional. Big Data melibatkan proses pembuatan data, penyimpanan, penggalian informasi, dan analisis yang menonjol dalam hal volume, velocity, dan variety.

Big Data adalah data yang melebihi proses kapasitas dari kovensi sistem database yang ada (Dumbill, 2012). Data terlalu besar dan terlalu cepat atau tidak sesuai dengan struktur arsitektur database yang ada. Untuk mendapatkan nilai dari data, maka harus memilih jalan altenatif untuk memprosesnya. Secara umum big data dapat diartikan sebagai sebuah kumpulan data yang berukuran sangat besar (volume), sangat cepat berubah/bertumbuh (velocity), hadir dalam beragam bentuk/format (variety). Serta memiliki nilai tertentu (value). Dengan catatan jika berasal dari sumber yang akurat (veracity).

Elemen penting dalam big data diantaranya:

1. Data (Facts, a description of the World)

2. Information (Captured Data and Knowledge): Merekam atau mengambil Data dan Knowledge pada satu waktu tertentu (at a single point). Sedangkan Data dan Knowledge dapat terus berubah dan bertambah dari waktu ke waktu.

3. Knowledge (Our personal map/model of the world): apa yang diketahui (not the real world itself) saat ini manusia tidak dapat menyimpan pengetahuan dalam diri manusia dalam apa pun selain otak, dan untuk membangun pengetahuan perlu informasi dan data.

Big data merupakan istilah untuk sekumpulan data yang begitu besar atau kompleks dimana tidak bisa ditangani lagi dengan sistem teknologi komputer konvensional (Hurwitz, Nugent, Halper, \& Kaufman, 2013).

\section{METODE}

\subsection{Khalayak Sasaran}

Sasaran pemberian Studi Pengenalan Internet of Things adalah 65 orang siswa dan guru SMK Bina Nusa Slawi yang dipandang ada kemauan dan minat untuk belajar, hal ini berdasarkan atas konsultasi dengan pihak SMK Bina Nusa Slawi. Dari khalayak sasaran yang strategis tersebut diharapkan berbagai informasi tentang tren Revolusi Industri 4.0 yang meliputi : Internet of Things, Artificial Intelligence, dan Big Data dapat diterima dengan baik oleh peserta kegiatan.

\subsection{Metode Kegiatan}

Metode kegiatan yang dilakukan untuk tercapainya tujuan Pengabdian Kepada Masyarakat ini adalah dengan metode presentasi dan diskusi. Presentasi yang dilakukan juga dibarengi dengan demonstrasi beberapa hal yang perlu didemokan seperti contoh dan cara kerja Intenet of Things, cara kerja Artificial Intelligence, dan cara kerja Big Data Analytic (pemaparan mengenai cara kerja Big Data pada Sosial Media maupun Search Engine, seperti : Google). Adapun demonstrasi tersebut didasari oleh evaluasi awal berupa pemaparan materi berupa presentasi yang telah disampaikan kepada peserta kegiatan. 


\subsection{Kerangka Pemecahan Masalah}

Berbagai potensi yang telah dijelaskan akan terealisasi dengan kerangka pemecahan masalah sebagai berikut :

1. Memberikan pengetahuani Guru dan Siswa SMK Bina Nusa Slawi mengenai Revolusi Industri 4.0 yang telah mendisrupsi hampir setiap bidang pekerjaan.

2. Memberikan pengetahuan kepada Guru dan Siswa SMK Bina Nusa Slawi mengenai Internet of Things yang merupakan salah satu ciri dari berkembangnya Revolusi Industri 4.0

3. Memberikan pemahaman kepada Guru dan Siswa Bina Nusa Slawi mengenai Artificial Intelligence sebagai bagian dari teknologi Internet of Things

4. Memberikan pemahaman kepada Guru dan Siswa Bina Nusa Slawi mengenai Big Data sebagai bagian dari teknologi Internet of Things

5. Memberikan demonstrasi penerapan Internet of Things, Artificial Intelligence, dan Big Data.

\subsection{Realisasi Pemecahan Masalah}

Dalam menyelesaikan masalah yang ada pada Guru dan Siswa SMK Bina Nusa Slawi yang terkait dengan Internet of Things, setelah dilakukan evaluasi awal terhadap pemahaman dan pengetahuan beberapa guru dan siswa, maka akan dilakukan perlakuan berupa presentasi materi, diskusi, dan demonstrasi sehingga diakhir kegiatan akan diperoleh hasil adanya peningkatan pengetahuan dan pemahaman Guru dan Siswa SMK Bina Nusa Slawi mengenai Intenet of Things sebagai ciri dari Revolusi Industri 4.0.

Terdapat beberapa materi yang disampaikan oleh tim pelaksana dalam kegiatan pengabdian kepada masyarakat ini dengan metode tertentu, diantaranya :

Tabel 2. Materi kegiatan dan metode pelaksanaan

\begin{tabular}{cll}
\hline No & \multicolumn{1}{c}{ Materi Kegiatan } & Metode Pelaksanaan \\
\hline 1 & Internet of Things & Presentasi Materi dan \\
& & Diskusi \\
2 & Artificial Intelligence & Presentasi Materi dan \\
& & Diskusi \\
3 & Big Data & Presentasi Materi dan \\
4 & Internet of Things, Artificial & Diskusi \\
& Demonstrasi \\
\hline
\end{tabular}

\section{HASIL DAN PEMBAHASAN}

Awal sebelum kegiatan dilaksanakan diadakan survey pendahuluan dan pemetaan calon peserta kegiatan pada tanggal 9 dan 10 Desember 2019 dengan Ketua Jurusan Multimedia, Ketua Jurusan Teknik Jaringan dan Komputer, Wakil Kepala Bidang Kesiswaan, Wakil Kepala Bidang Hubungan Masyarakat, dan Kepala SMK Bina Nusa Slawi oleh tim pelaksana kegiatan Pengabdian Kepada Masyarakat. Hasil survey membuktikan bahwa pengetahuan dan pemahaman $99 \%$ guru dan siswa mengenai konsep dan implementasi Internet of Things masih sangat minim, baik mengenai konsep, penerapan dan tren yang terdapat di era revolusi industri 4.0. Disamping itu juga beberapa guru dan siswa juga belum faham mengenai komponen Intenet of Things, yang diantaranya adalah Artificial Intelligence dan Big Data.

Kegiatan Pengabdian Kepada Masyarakat diselenggarakan pada tanggal 16 s.d 17 Desember 2019 yang dilakukan dengan metode presentasi dan diskusi serta demonstrasi contoh penerapannya. Presentasi dilakukan untuk menyampaikan materi tentang Internet of Things, Artificial Intelligence, dan Big Data. Sedangkan demonstrasi dilakukan dengan mempraktikan dan mendemonstrasikan penerapan teknologi Internet of Things, Artificial Intelligence, dan Big Data.

1. Presentasi dan Diskusi

Presentasi yang disampaikan oleh tim pelaksana kegiatan dilaksanakan pada hari pertama di aula SMK Bina Nusa Slawi. Pelaksanaan kegiatan presentasi ini adalah memberikan pengetahuan dan pemahaman kepada guru dan siswa SMK Bina Nusa Slawi mengenai Internet 
of Things sebagai ciri dari Revolusi Industri 4.0. Pada sesi ini peserta diberikan materi mengenai Internet of Things, Artificial Intelligence, dan Big Data. Disamping itu peserta juga diberikan kesempatan untuk berdiskusi secara interaktif mengenai konsep, penerapan dan pemanfaatan, serta prediksi penggunaan masa depan teknologi Internet of Things, Artificial Intelligence, dan Big Data yang telah menghilangkan profesi / pekerjaan seseorang, akan tetapi memunculkan pekerjaan baru. Pada sesi ini peserta mendapatkan banyak pengetahuan mengenai makna disrupsi pada era revolusi industri 4.0, sehingga bagi peserta yang terutama guru bisa mempersiapkan strategi pembelajaran dan konten pembelajaran yang dapat dipersiapkan untuk siswanya saat proses kegiatan belajar mengajar, untuk menjadikan siswanya bisa lebih kompetitif dan adaptif terhadap perubahan yang begitu cepat.

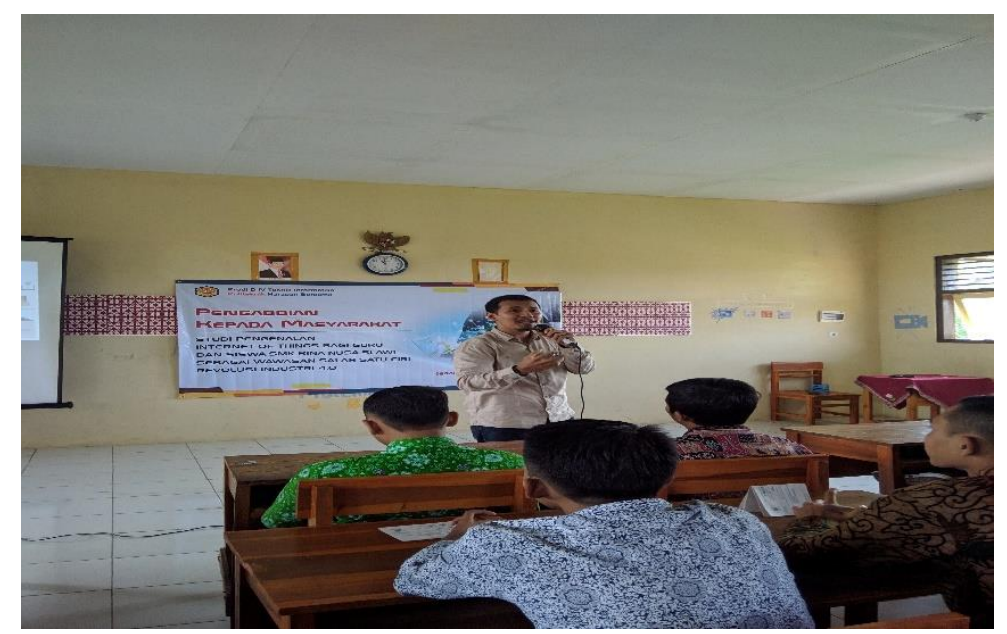

Gambar 1. Pelaksanaan Presentasi materi dan diskusi

\section{Demonstrasi}

Kegiatan demonstrasi ini dilakukan pada tanggal 17 Desember 2019 di ruang auditorium SMK Bina Nusa Slawi yang disampaikan langsung oleh tim mahasiswa dan dosen pendamping. Adapun materi yang disajikan adalah mengenai Internet of Things, Artificial Intelligence, dan Big Data dengan rincian sebagai berikut :

a. Pada sesi Internet of Things, mahasiswa menyajikan dan mendemonstrasikan miniatur smart home, dimana beberapa peralatan rumah tangga seperti lampu dan pintu dapat dikontrol menggunakan aplikasi smartphone dan ucapan sebuah kata (Speech Recognition).

b. Pada sesi Artificial Intelligence, mahasiswa menyajikan dan mendemonstrasikan aplikasi mobile yang bisa deteksi/scan emosional orang (Emotional Detection), yang dilihat dari bentuk muka, bentuk bibir, dan mata.

c. Pada sesi Big Data, mahasiswa menyajikan dan mendemonstrasikan Big Data Analytics pada sosial media, dimana mahasiswa melakukan scraping data, collection data, cleaning data dan sampai tahap analisis data.

Pada sesi ini peserta diberikan kesempatan untuk diskusi dan konsultasi dengan tim mahasiswa mengenai teknis-teknis penerapan teknologi Internet of Things, Artificial Intelligence, dan Big Data. Disamping itu, pada kegiatan ini juga tim mahasiswa menjelaskan konsep dalam mengkolaborasikan ketiga teknologi tersebut, yakni : Internet of Things, Artificial Intelligence, dan Big Data dalam tren yang sekarang ada didunia industri. 


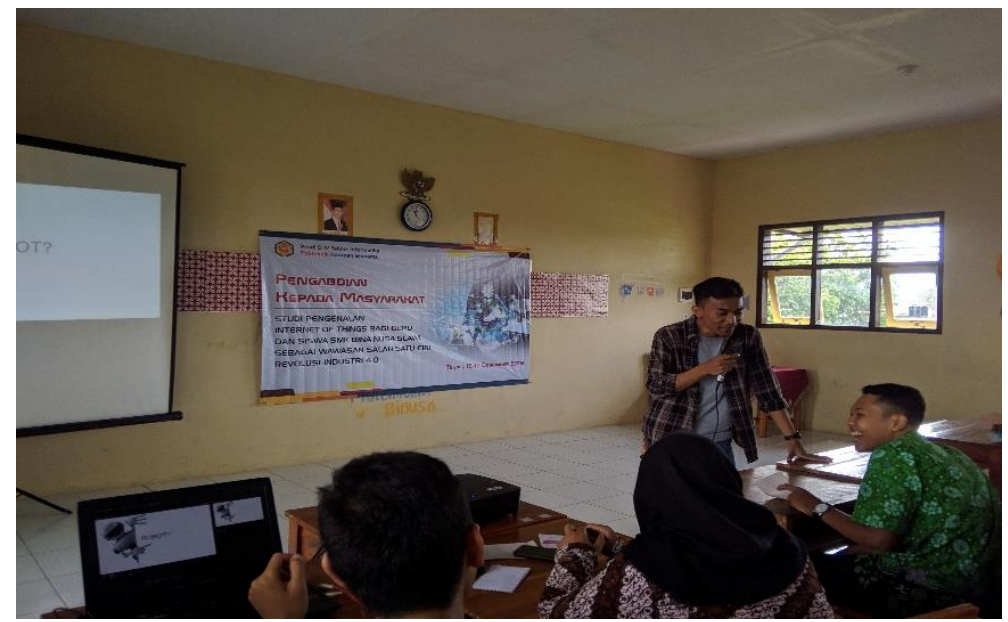

Gambar 2. Demonstrasi penerapan teknologi oleh mahasiswa

Setelah kegiatan Presentasi - Diskusi serta Demonstrasi selesai dilaksanakan, kemudian dilakukan sebuah post test untuk menggali informasi mengenai pemahaman peserta, maka dihasilkan bahwa $100 \%$ peserta yang mengikuti kegiatan secara utuh, pengetahuan dan pemahamannya mengenai Revolusi Industri 4.0, Internet of Things, Artificial Intelligence, dan Big Data semakin baik dan meningkat, tidak hanya pemahaman pada hal konsep, akan tetapi sampai pada tahap implementasi / penerapan dan mengkolaborasikan ketiga teknologi tersebut.

Dalam pelaksanaan kegiatan terdapat faktor-faktor yang mempengaruhi kegiatan, diantaranya :

1. Faktor Pendukung

Yang menjadi faktor pendukung dalam kegiatan pengabdian ini adalah :

a. Semua peserta kegiatan telah familiar dengan komputer

b. Dukungan yang sangat baik oleh Kepala Sekolah

c. Ruang auditorium untuk pelaksanaan kegiatan yang cukup representatif

d. Antusiasme dan partisipasi aktif dari siswa dan guru SMK Bina Nusa Slawi dalam mengikuti kegiatan ini.

e. Fasilitas kegiatan Pengabdian yang disediakan oleh institusi SMK Bina Nusa Slawi

2. Faktor Penghambat

a. Pengetahuan, pemahaman, dan kompetensi peserta yang heterogen, sebab terdiri dari guru dan siswa

b. Keterbatasan bandwith internet di SMK Bina Nusa Slawi, sehingga demonstrasi kurang optimal

c. Waktu demonstrasi yang disediakan kurang lama sehingga kurang optimal.

\section{KESIMPULAN}

Berdasarkan hasil kegiatan Studi Pengenalan Internet of Things Bagi Guru dan Siswa SMK Bina Nusa Slawi Sebagai Wawasan Salah Satu Ciri Revolusi Industri 4.0 dapat disimpulkan bahwa Pengetahuan dan pemahaman Guru dan Siswa SMK Bina Nusa Slawi mengenai Revolusi Industri 4.0, Internet of Things, Artificial Intelligence, dan Big Data semakin baik dan meningkat, tidak hanya pemahaman pada hal konsep, akan tetapi sampai pada tahap implementasi / penerapan dan mengkolaborasikan ketiga teknologi tersebut.

\section{DAFTAR PUSTAKA}

Dumbill, E. (2012). Big Data Now: 2012 Edition. “What Is Big Data? USA: O’Reilly Media, Inc.

Elkhodr, M., Shahrestani, S., \& Cheung, H. (2012). A review of mobile location privacy in the Internet of Things. International Conference on ICT and Knowledge Engineering. https://doi.org/10.1109/ICTKE.2012.6408566 
Hermann, M., Pentek, T., \& Otto, B. (2016). Design principles for industrie 4.0 scenarios. Proceedings of the Annual Hawaii International Conference on System Sciences, 2016-March, 3928-3937. https://doi.org/10.1109/HICSS.2016.488

Hurwitz, J., Nugent, A., Halper, F., \& Kaufman, M. (2013). Big Data for Dummies. In Wiley. https://doi.org/10.1007/s13398-014-0173-7.2

Industri, R., Tantangan, D. A. N., \& Sosial, P. (2018). Revolusi Industri 4.0 Dan Tantangan Perubahan Sosial. (5), 22-27. https://doi.org/10.12962/j23546026.y2018i5.4417

Jogiyanto \& Abdillah. (2011). Sistem Tata Kelola Teknologi Informasi. Yogyakarta: Andi.

Kadir, A. dan T. C. (2005). Pengenalan Teknologi Informasi. Yogyakarta: Andi.

Keoh, S. L., Kumar, S. S., \& Tschofenig, H. (2014). Securing the internet of things: A standardization perspective. IEEE Internet of Things Journal, 1(3), 265-275. https://doi.org/10.1109/JIOT.2014.2323395

Kusumadewi, S. (2003). Artificial Intelligence (Teknik dan Aplikasinya). Yogyakarta: Graha Ilmu.

Shwab, K. (2016). The Fourth Industrial Revolution. New York: Crown Business.

Supriyanto, A. (2005). Pengantar teknologi Informasi. Jakarta: Salemba Infotek.

Suresh, P.; Daniel, J. Vijay; Aswathy, R. H. . (2014). A state of the art review on the Internet of Things (IoT) history, technology and fields of deployment. 2014 International Conference on Science Engineering and Management Research (ICSEMR). https://doi.org/10.1109/ICSEMR.2014.7043637

The institute of Interbal auditors. (2017). PERSPEKTIF DAN PANDANGAN GLOBAL Kecerdasan Buatan (Artificial Intelligence/AI) - Pertimbangan untuk Profesi Audit Internal. 1-9.

Tjandrawinata, R. (2016). Industri 4.0: revolusi industri abad ini dan pengaruhnya pada bidang kesehatan dan bioteknologi. 29(1), 31-39. https://doi.org/10.5281/zenodo.49404

Wang, C., Daneshmand, M., Dohler, M., Mao, X., Hu, R. Q., \& Wang, H. (2013). Guest Editorial Special Issue on Internet of Things (IoT): Architecture, Protocols and Services. IEEE Sensors Journal, 13(10), 3505-3510. https://doi.org/10.1109/JSEN.2013.2274906

William and Sawyer. (2007). Using Information Technology. Yogyakarta: Andi.

Zhou, Qilou \& Zhang, J. (2011). Internet of Things and Geography Review and Prospect. International Conference on Multimedia and Signal Processing, 47-51. https://doi.org/https://doi.org/10.1109/CMSP.2011.101 